\title{
On the Tidal Resonance of the Bristol Channel
}

\author{
C. Gao and T. A. A. Adcock \\ Department of Engineering Science, University of Oxford, United Kingdom
}

\begin{abstract}
The Bristol Channel has one of the largest tidal ranges in the world. A key cause for this is the resonance with the dominant semi-diurnal tides. In this paper we use numerical simulations to investigate this resonance. We first vary the frequency on the boundary of the model and examine at which frequency the model is excited. Secondly we apply a disturbance to the model and analyse the period at which it resonates. We examine the sensitivity of these results finding them sensitive to the bed friction used (with possible implications for energy extraction) but insensitive to small changes in the tidal amplitude on the boundary or the mean-water level.
\end{abstract}

KEY WORDS: ADCIRC, tidal resonance, shallow water equations, numerical modelling, Bristol Channel.

\section{INTRODUCTION}

The Bristol Channel and Severn Estuary constitute one of the largest, semienclosed water basins in the UK. The Bristol Channel is located in the south-west coast of Great Britain. The Severn Estuary is situated at the upper reaches of the Bristol Channel, which has second largest semi-diurnal tidal ranges worldwide. The typical mean spring tidal range is $12.2 \mathrm{~m}$, with the high spring tidal range approaching $14 \mathrm{~m}$ at the Severn mouth. The large tidal ranges observed in the Bristol Channel and the Severn Estuary are driven by two main mechanisms (Robinson, 1980; Xia et al., 2012; Serhadlıoğlu, 2014). One is the funnelling effect at the upper reaches of the Bristol Channel due to its wedge-shaped geometry and shallow bathymetry. However, it has long been pointed out by Marmer (1922) that this effect is not enough to produce the observed tidal range. The other mechanism is the quarter wavelength resonance of the Channel with the incident North Atlantic tidal wave (Fong and Heaps, 1978).

Despite a number of previous model studies having been undertaken for the Bristol Channel, the complex hydrodynamic system of the Channel is not yet fully understood, particularly given its resonant nature. Resonant systems are typically very sensitive to small changes and these responses are highly site dependent (Adcock et al., 2015). In this study we seek to improve the understanding of the resonance in the Bristol Channel. A simplified two-dimensional model has been developed from Serhadlıoglu's (2013) model to investigate the resonances in the Bristol Channel.

In this paper, the model equations and the model parameters used for the Bristol Channel region are firstly considered. Then, the model is tested by comparing its results with previous model studies and observations. Two methods have been used to determine the resonant periods of the Bristol Channel. A frequency sweep is used by varying the forcing frequency on the open boundary of the model to find the peak response of the semi-diurnal tidal amplitude. Next, the key properties that influence the resonances are investigated. Finally, wind disturbances are applied to examine the oscillation periods of surge response.

\section{RELATED WORK}

Systems that are forced by oscillations close to their natural period have large amplitude responses. This phenomenon is called resonance (Pugh, 1996). In oceanography, a tidal resonance occurs when the tide excites one of the resonant modes of the ocean. This occurs when a continental shelf is about a quarter wavelength wide. The whole global ocean system seems to be near to resonance at semidiurnal tidal frequencies and the observed tides are substantially larger than the Equilibrium Tide (Baker, 1991; Pugh and Woodworth, 2014).

In some studies, the phenomenon of quarter wavelength resonance was explained by standing wave theory (Pugh, 1996; Pugh and Woodworth, 2014). Consider the simplest case of a wave travelling in a long channel being reflected without loss of amplitude at a closed end. The superposition of incident and reflected waves can resemble a standing wave which have alternate nodes, positions where the amplitude is zero, and antinodes, positions where the amplitude is a maximum, each separated by a distance $\lambda / 4$ where $\lambda$ is the wavelength of the original progressive wave (Pugh, 1996). A model of an open box approximates to the tidal behaviour of many shelf sea basins (Pugh, 1996). If we describe the movement of water in a box whose length is a quarter wavelength with one closed end and one open end, and the water is driven by oscillatory in and out currents at the open end, thus the open end is at the first node and currents at the entrance could produce large changes of level at the head. Although exact quarter-wave dimension would be very unlikely, the possibility of tidal amplification still exists.

The resonances in the Bristol Channel have practical significance and theoretical interest. Tidal power barrages in the Severn estuary, Bristol Channel were studied intensively in the 1980 s, by a UK government committee chaired by Bondi (see Bondi et al., 1981). The suitability of tidal stream turbine deployment sites in Wales along the Bristol Channel has also been studied by Willis et al (2010). The tidal lagoon project in the vicinity of the Port of Swansea, South Wales, was developed in 2010 and will be started on site around 2017. Therefore, to assess how these might alter the tidal characteristics of the area it is obviously important to understand the tidal dynamics as they presently exist (Fong and Heaps, 1978).

In recent years, the Bristol Channel and Severn Estuary has been of particular interest to engineers and scientists for this reason and several studies have been undertaken over the past 30 years or so. Serhadlığlu (2014) presented an extended table of the significant numerical studies of estimating the resonant period of the Bristol Channel/Celtic Sea system from Fong and Heaps's (1978). Table 1 is an extended version of Serhadlıoğlu's. Serhadlıoğlu (2014) has worked on the reso- 
Table 1. Estimates of the fundamental seiche period of the Bristol Channel and the Celtic Sea derived from various theoretical models (extended table taken from Serhadlığlu (2014)).

\begin{tabular}{|c|c|c|c|c|c|}
\hline References & Comment & Areas included & $\begin{array}{l}\text { Friction coeffi- } \\
\text { cient }\end{array}$ & Fundamental period (hours) & $\begin{array}{ll}\text { Frequency ratio } \\
\omega / \omega_{M_{2}}\end{array}$ \\
\hline $\begin{array}{l}\text { Fong and Heaps } \\
\text { (1978) }\end{array}$ & $\begin{array}{l}\text { 1-D numerical model to investigate } \\
\text { the quarter-wave tidal resonance in } \\
\text { the Bristol Channel-Celtic Sea shelf } \\
\text { area }\end{array}$ & $\begin{array}{l}\text { Celtic Sea and Bristol } \\
\text { Channel }\end{array}$ & Not included & Celtic Sea: $12.2-12.6$ & $0.98-1.02$ \\
\hline Heath (1981) & $\begin{array}{l}\text { A linear resonant model fitted to the } \\
\text { semi-diurnal tidal constituents }\end{array}$ & Ocean and Celtic Sea & Not included & $\begin{array}{l}\text { Celtic Sea: 10.8-11.1; Bristol } \\
\text { Channel: } 7.3-9.0\end{array}$ & $\begin{array}{l}\text { Celtic } \quad \text { Sea: } \\
1.12-1.15 ; \text { Bris- } \\
\text { tol Channel: } \\
1.38-1.7\end{array}$ \\
\hline Webb (2013) & $\begin{array}{l}\text { 2-D numerical model to investigate } \\
\text { the resonances of the English Chan- } \\
\text { nel and Irish Sea }\end{array}$ & $\begin{array}{l}\text { European continental } \\
\text { shelf, English Channel, } \\
\text { Bristol Channel and Irish } \\
\text { Sea }\end{array}$ & $\kappa=0.2 \mathrm{~cm} \mathrm{~s}^{-1}$ & $\begin{array}{l}\text { Portishead in the Bristol Chan- } \\
\text { nel: } 10.8-11.6\end{array}$ & $1.07-1.15$ \\
\hline 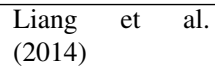 & $\begin{array}{l}\text { 1-D computational model to predict } \\
\text { the tidal characteristics response }\end{array}$ & $\begin{array}{l}\text { Severn Estuary and Bristol } \\
\text { Channel }\end{array}$ & $\begin{array}{l}\text { Roughness } \\
\text { height: } 35 \mathrm{~mm}\end{array}$ & Bristol Channel: 8-9 & $1.38-1.55$ \\
\hline $\begin{array}{l}\text { Serhadlı̆̆glu } \\
\text { (2014) }\end{array}$ & $\begin{array}{l}\text { 2-D unstructured computational } \\
\text { model to investigate the resonance } \\
\text { of the system }\end{array}$ & $\begin{array}{l}\text { European continental } \\
\text { shelf, Irish Sea, Celtic Sea } \\
\text { and Bristol Channel }\end{array}$ & 0.0025 & Bristol Channel: 10.3-11.3 & $1.1-1.2$ \\
\hline
\end{tabular}

nance in Bristol Channel using a two-dimensional unstructured triangular model mesh, which was the one that the present study built on. The model domain includes the Irish Sea, the Celtic Sea, the English Channel and the Bristol Channel. In Serhadlığlu's study the model was excited with a single tidal component with the amplitude of the $M_{2}$ tide (principal lunar semi-diurnal tidal constituent) but with the frequency varied, and a resonant period of 10.3-11.3 hours was found.

\section{METHOD}

\section{Shallow Water Equations}

A simplification can be made by integrating the horizontal velocity over the vertical direction to obtain a representative velocity flow field, which satisfies the shallow water equations (SWEs). The two-dimensional SWEs consist of the depthaveraged continuity equation and the $x$ and $y$ momentum equations written here in conservative form:

$\frac{\partial \zeta}{\partial t}+\frac{\partial}{\partial x}(H u)+\frac{\partial}{\partial y}(H v)=0$

$\frac{\partial}{\partial t}(u H)+\frac{\partial}{\partial x}\left(H u^{2}+\frac{1}{2} g\left(H^{2}-h^{2}\right)\right)+\frac{\partial}{\partial y}(H u v)=g \zeta \frac{\partial h}{\partial x}-c_{f} u \sqrt{u^{2}+v^{2}}+f v+F_{x}$

$\frac{\partial}{\partial t}(v H)+\frac{\partial}{\partial y}\left(H v^{2}+\frac{1}{2} g\left(H^{2}-h^{2}\right)\right)+\frac{\partial}{\partial x}(H u v)=g \zeta \frac{\partial h}{\partial y}-c_{f} v \sqrt{u^{2}+v^{2}}-f u+F_{y}$

where $H$ is the total depth of the water column $(H=h+\zeta)$, which is equivalent to the sum of the free surface elevation $(\zeta)$ and the bathymetric depth, $h$. The variables $u$ and $v$ represent the depth-averaged velocity components in $x$ - and $y-$ directions. $g$ is the gravitational acceleration, $c_{f}$ is the bottom drag coefficient, $f$ is the Coriolis parameter, the multiplication of this parameter by the speed gives the Coriolis 'force', and $F_{x}$ and $F_{y}$ represent additional forces in the system such as tidal potential forces, wind or wave radiation stresses (Falconer, 1993). Due to the large tidal range and relatively small river discharge, the flow in the Severn Estuary and Bristol Channel does not display any significant stratification, which justifies the use of the shallow water equations in the hydrodynamic analyses (Liang et al., 2014).

The discontinuous Galerkin, DG, is a class of finite element methods which makes use of the same function space as the continuous method, but with relaxed continuity at inter-element boundaries (Kubatko et al., 2006). In this study, the shallow water equations were solved using the discontinuous Galerkin (DG) version of ADCIRC, which is a well-developed hydrodynamic finite element model. ADCIRC is widely used for tide and surge modelling, and is in constant development, with work ongoing in the areas of adaptive grids, three-dimensional modelling, sediment transport and biological processes (Kubatko et al., 2006).

\section{Model Set Up}

The model was built from Serhadlıoğlu's study (2014) whose modelling region includes the Irish Sea, the Celtic Sea and the Bristol Channel. An unstructured mesh was developed by the ADvanced CIRCulation model (ADCIRC) with Surface-water Modelling System (SMS). A mesh convergence study has been conducted to evaluate the necessary level of resolution required in the numerical model to obtain a converged $M_{2}$ response using five unstructured triangular finite element meshes (Serhadlıoğlu, 2014). On the open boundary, the water depths were prescribed and were the best estimates based on previous work (Serhadlığlu et al., 2013), and no current was specified on the boundary.

As seen in Fig. 1, the model domain stretches from the outer Bristol Channel, close to Lundy Island, to Caldicot and thereby includes the entire expanse of water from the open sea to the tidal limit. The domain is approximately $160 \mathrm{~km}$ long, narrowing down dramatically towards the head of the Estuary, from around $112 \mathrm{~km}$ at the seaward boundary to about $1.4 \mathrm{~km}$ at the landward boundary. The coastline in the model region is interpolated with a mean sea level of $6 \mathrm{~m}$, and the water depth ranges from $-65 \mathrm{~m}$ to $+9 \mathrm{~m}$ from seaward boundary to the riverine boundary. The model domain was divided into 14606 unstructured triangular cells and allows a large variation in the scales of regions of interest, which in this study varies from $500 \mathrm{~m}$ to $5000 \mathrm{~m}$. Five stations Avonmouth, Newport, Hinkley Point, Mumbles and Ilfracombe were chosen as the observation stations.

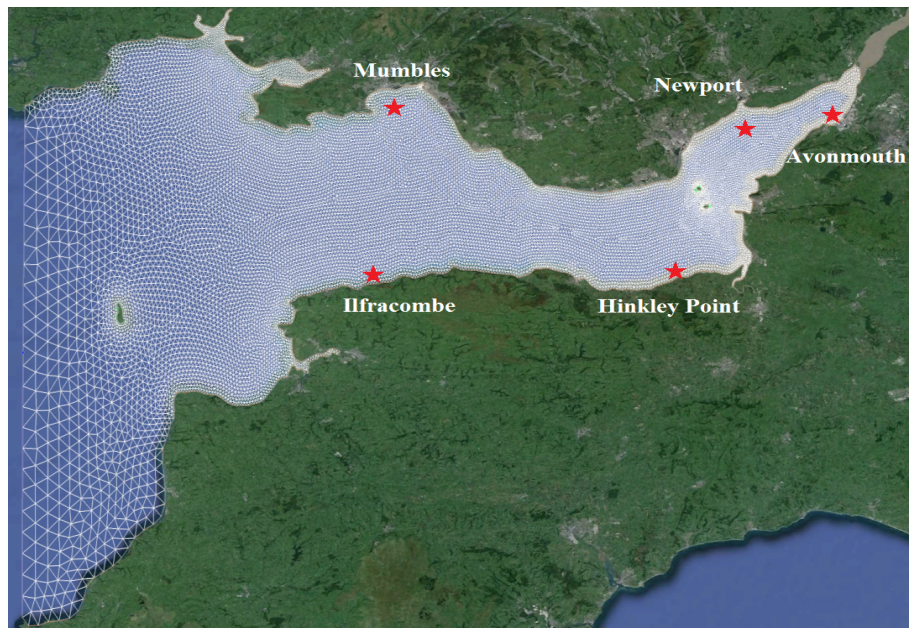

Fig. 1 Model mesh shown in Google Earth (Google Earth, 2016). 
Table 2. Comparison of the observed $M_{2}$ tidal elevations and phases against model results using various bed friction coefficients. The values highlighted in grey are the ones that are closer to the observations in the case of amplitude and closer to the observations with a $5^{\circ}$ shift in the case of phase.

\begin{tabular}{|l|c|c|c|c|c|c|c|c|c|c|}
\hline \multirow{2}{*}{ Station } & \multicolumn{9}{|c|}{ Amplitude $(\mathrm{m})$} & \multicolumn{5}{c|}{ Phase $\left(^{\circ}\right)$} \\
\cline { 2 - 11 } & Obs. & 0.0025 & 0.0035 & 0.004 & 0.005 & Obs. & 0.0025 & 0.0035 & 0.004 & 0.005 \\
\hline Stackpole Quay $\left(51.63^{\circ} \mathrm{N}, 4.85^{\circ} \mathrm{W}\right)$ & 2.51 & 2.52 & 2.52 & 2.51 & 2.51 & 168 & 172 & 172 & 172 & 172 \\
\hline Mumbles $\left(51.57^{\circ} \mathrm{N}, 4^{\circ} \mathrm{W}\right)$ & 3.18 & 3.10 & 3.05 & 3.04 & 3.01 & 171 & 173 & 176 & 176 & 178 \\
\hline Swansea $\left(51.62^{\circ} \mathrm{N}, 3.93^{\circ} \mathrm{W}\right)$ & 3.19 & 3.15 & 3.12 & 3.10 & 3.03 & 173 & 174 & 176 & 177 & 179 \\
\hline Port Talbot $\left(51.58^{\circ} \mathrm{N}, 3.78^{\circ} \mathrm{W}\right)$ & 3.13 & 3.17 & 3.15 & 3.12 & 3.07 & 173 & 174 & 176 & 177 & 179 \\
\hline Barry $\left(51.4^{\circ} \mathrm{N}, 3.28^{\circ} \mathrm{W}\right)$ & 3.92 & 3.90 & 3.80 & 3.74 & 3.62 & 185 & 182 & 187 & 190 & 193 \\
\hline Steep Holm island $\left(51.33^{\circ} \mathrm{N}, 3.1^{\circ} \mathrm{W}\right)$ & 3.87 & 4.04 & 3.94 & 3.88 & 3.75 & 186 & 183 & 189 & 191 & 196 \\
\hline Cardiff $\left(51.48^{\circ} \mathrm{N}, 3.17^{\circ} \mathrm{W}\right)$ & 4.01 & 4.07 & 3.95 & 3.89 & 3.79 & 191 & 186 & 190 & 193 & 199 \\
\hline Weston-super-Mare $\left(51.35^{\circ} \mathrm{N}, 2.97^{\circ} \mathrm{W}\right)$ & 3.95 & 4.17 & 4.01 & 4.00 & 3.87 & 181 & 184 & 189 & 193 & 199 \\
\hline Hinkley Point $\left(51.2^{\circ} \mathrm{W}, 3.13^{\circ} \mathrm{W}\right)$ & 3.8 & 4.00 & 3.89 & 3.83 & 3.71 & 195 & 181 & 186 & 188 & 193 \\
\hline Minehead $\left(51.2^{\circ} \mathrm{N}, 3.47^{\circ} \mathrm{W}\right)$ & 3.59 & 3.70 & 3.64 & 3.59 & 3.49 & 183 & 176 & 180 & 182 & 186 \\
\hline Porlock Bay $\left(51.22^{\circ} \mathrm{N}, 3.6^{\circ} \mathrm{W}\right)$ & 3.42 & 3.54 & 3.47 & 3.43 & 3.36 & 179 & 173 & 176 & 178 & 181 \\
\hline Ilfracombe $\left(51.2^{\circ} \mathrm{N}, 4.12^{\circ} \mathrm{W}\right)$ & 3.04 & 3.00 & 2.99 & 2.97 & 2.94 & 162 & 165 & 166 & 167 & 168 \\
\hline Appledore $\left(51.05^{\circ} \mathrm{N}, 4.18^{\circ} \mathrm{W}\right)$ & 2.57 & 2.62 & 2.59 & 2.57 & 2.52 & 165 & 170 & 172 & 173 & 174 \\
\hline Port Isaac $\left(50.58^{\circ} \mathrm{N}, 4.82^{\circ} \mathrm{W}\right)$ & 2.47 & 2.42 & 2.42 & 2.42 & 2.41 & 144 & 151 & 151 & 151 & 151 \\
\hline
\end{tabular}

From tidal analysis, the dominant constituent in the Bristol Channel is the $M_{2}$, followed by the $S_{2}$ (principal solar semi-diurnal constituent), $N_{2}$ (larger lunar elliptic semi-diurnal constituent) and $\mu_{2}$ (variational semi-diurnal constituent) (Hashemi et al., 2008), but in this study attention is restricted to the dominant harmonic constituent, the $M_{2}$ tide. The ocean boundary was forced with a single sinusoidal constituent with an amplitude distribution across the boundary given by that of the $M_{2}$ constituent interpolated from the same model (Serhadlığlu et al., 2013). The DG-ADCIRC modelling parameters were set as constant throughout the study: most of them were attained as the default values recommended by the ADCIRC model developers, some are same with that of Serhadlıoglu's study; while the rest, such as time step, bottom friction, wetting and drying were determined using equations and a parameter sensitivity analysis for the area of focus. Initially, the simulations were run without any meteorological input, in order to observe the general flow of tides through the region.

\section{RESULTS AND DISCUSSION}

\section{Model Calibration}

In order to achieve the most accurate results, the model was tuned by adjusting the quadratic bottom friction coefficient $\left(c_{f}\right)$ until the model predicted and observed $M_{2}$ tidal elevations and phases were in closest agreement. The observational data were from the United Kingdom and Ireland Admiralty tide tables. The final results for fourteen calibration sites are summarised in Table 2. The computed $M_{2}$ phases at both ends of the ocean boundary (Stackpole Quay and Port Isaac) show a $4^{\circ}-7^{\circ}$ shift from the observed values. Therefore the computed phases that are around $5^{\circ}$ larger than the observed values should be the best fit for model calibration. It is seen from the table that the model results show a good agreement with the observed data when using a bed friction coefficient $c_{f}=0.004$. However, this estimation is an average for the entire area and do not reflect real spatial variability in frictional forces.

\section{Quarter-wave Tidal Resonance?}

Looking ahead the response of the system using the natural forcing frequency $\left(\omega / \omega_{M_{2}}=1.0\right)$, it is found that the dominant frequency of the Bristol Channel response is larger than the natural frequency (Fig. 3-7), which indicates that the basin length of the Bristol Channel is shorter than the quarter wavelength required for resonance. This is consistent with the result if we compare the $M_{2}$ quarter wavelength with the length of the Channel. Tidal waves in the Bristol Channel behave as "long waves" since their wavelength is much greater than the water depth implying vertical motion may be neglected. The wavelength of a shallow water wave is given by the formula below:

$L=\frac{2 \pi \sqrt{g H}}{\sigma}$

where $g$ is the gravitational acceleration $\left(m s^{-2}\right), H$ is the water depth (m) and $\sigma$ is the angular frequency of the tidal component (radians $s^{-1}$ ) (Godin, 1993). If we take $H \approx 40 \mathrm{~m}$ for the Bristol Channel, since $\sigma=1.405 \times 10^{-4} \mathrm{~s}^{-1}$ for the constituent $M_{2}$, we find $\frac{1}{4} L=221 \mathrm{~km}$ for the Bristol Channel. This model shows that the length of the Channel is around $160 \mathrm{~km}$, therefore somewhat shorter than an $M_{2}$ quarter wavelength. It is presented in the theory of tidal resonance that the basin must satisfy the well-known quarter wavelength requirement. Godin (1993) found that the restricted concept was a necessary but not sufficient condition for the phenomenon to occur, especially for deeper embayments. Serhadlıoğlu (2014) found the Bristol Channel is shorter than the quarter wavelength for the $M_{2}$ tidal period. The results presented in this paragraph agree with previous findings and suggest the quarter wavelength requirement may as well become more relaxed for shallow basins.

\section{Resonant Periods}

The $M_{2}$ response curves of the Bristol Channel have been investigated by exciting the model using artificially altered $M_{2}$ forcing frequencies $(\omega)$, and applying a ratio $\left(\omega / \omega_{M_{2}}\right)$ varying between 0.5175 and 5.175. The simulated results of $M_{2}$ elevations were recorded at 16 stations along the Bristol Channel and at 5 stations across the mid-Channel (Fig. 2). Station C is overlapped with ST11.

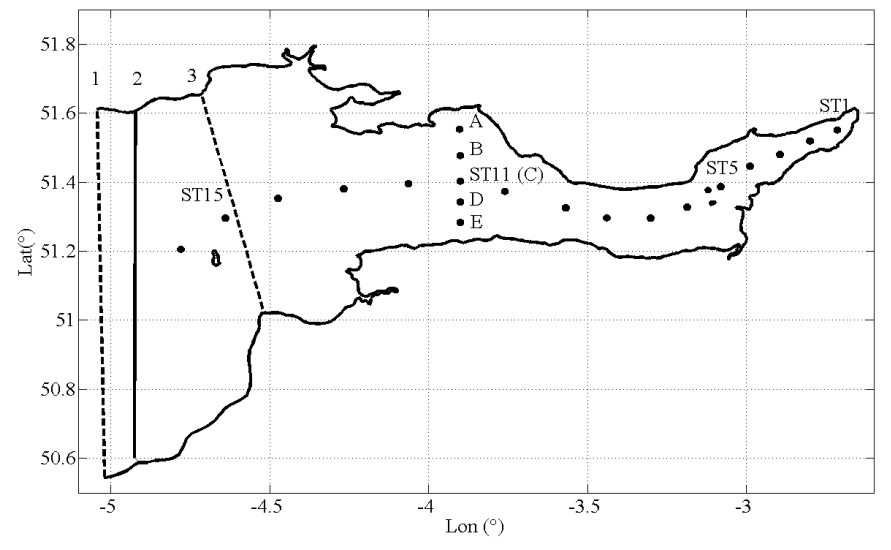

Fig. 216 stations along the Channel and 5 stations across the mid-Channel with boundary 1,2 3 from left to right (the original boundary is boundary 2).

The response curves of several stations taken along the Bristol Channel are plotted in Fig. 3, in which four stations (ST3/5/7/9) were chosen to represent the inner section of the Channel while three stations (ST11/13/15) represent the outer Channel. In Fig. 3, the response curves follow a similar pattern at all the stations considered, but differ in magnitude due to the location of the observation station. 


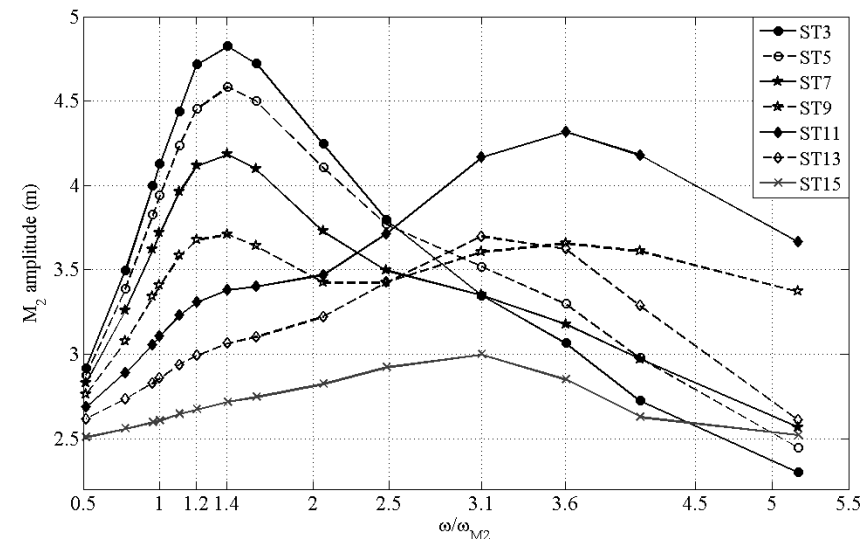

Fig. 3 The response curves of several stations along the Bristol Channel: ST3, ST5, ST7 and ST9 represent the inner Channel response; ST11, ST13 and ST15 represent the outer Channel response.

It is shown that all the stations show a peak in response at around a ratio of 1.2-1.4 which indicates the quarter wavelength resonance of the system with a period of approximately 8.87-10.35 hours. A second peak is observed at $\omega / \omega_{M_{2}}=3.1-3.6$ in the outer Channel, and the peak variation is seen to be very site-dependent. Equation (4) suggests, this may be a resonance occurring at the Channel entrance.

Fig. 4 shows the response curves of all the five stations across the mid-Channel. It is seen that at around the forcing frequency of $\omega / \omega_{M_{2}}=3-4$ there is a significant increase in the $M_{2}$ amplitude response. When approaching the coasts, the response slightly increases which is probably due to the decrease in water depth. Increases of response amplitudes in Station A and B are more obvious, this may attribute to the topography of the coast near them compared to the other side.

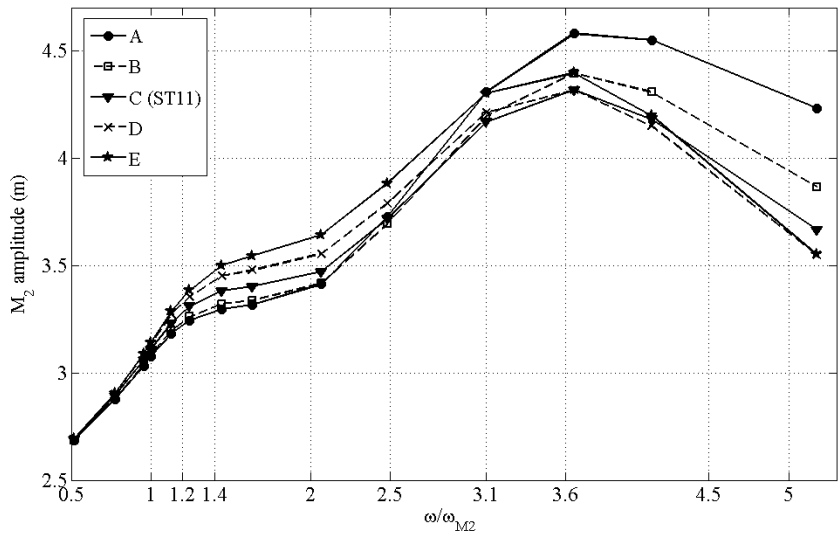

Fig. 4 Response curves of stations across the mid-Channel near Swansea Bay.

The resonant period calculated from this model result is within range suggested by previous studies, which suggested a resonant period between 7.3 to 11.3 hours (Table 1). The method used in this study was same with Serhadlıoglu (2014) but the dominant tidal period obtained here is slightly lower than in her study. This subtle difference might be due to the coupled nature of two different modelling systems and this reason was also suggested by Serhadlığlu (2014). In the present study the model domain only includes the Bristol Channel while in Serhadlığlu's study the Irish Sea, the Celtic Sea, English Sea and Bristol Channel are all included. Results from Table 1 also indicate that when the Celtic Sea is included in the model the resonant period is likely to be larger compared to that only includes the Bristol Channel. Additionally, the present model applies a coarser mesh than the one of Serhadlığlu's. These may both contribute to the peak shift of the resonant response.
Fig. 5 illustrates the amplification of the response along the Bristol Channel by normalising the response of the Channel by the elevation at the Channel mouth (solid line). The figure also shows the amplification within the inner Channel and in the outer Channel. The inner section of the Bristol Channel shows an amplified response over the frequency range $\omega / \omega_{M_{2}}$ ratio of 1.2-1.5 while the outer part of the Channel (dotted line) exhibits an apparent resonance around the ratio of 4.1. The result indicates a coupled resonant system of the Bristol Channel: the main peak might be the dominant resonant mode of the Bristol Channel, while the second peak might be due to the response of the Channel to the forcing at its mouth. This complicated resonance pattern was also found by Liang et al. (2014). They suggested that some regions in the outer Bristol Channel also experience significant, if not greater, resonances when the $\omega / \omega_{M_{2}}$ ratio $=3-6$.

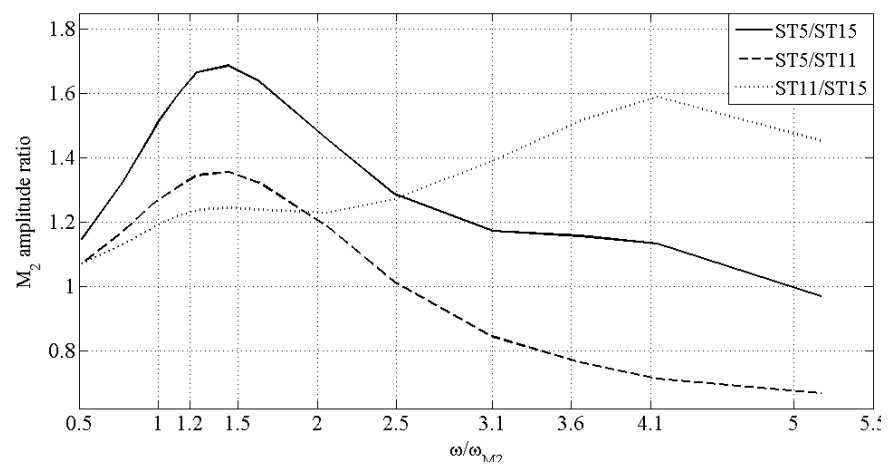

Fig. 5 Amplification of the response observed in the Channel.

Fig. 6 present the comparison of $M_{2}$ response curves obtained from the models with three different boundary positions (shown in Fig. 2). Boundary 2 is the original one adopted in this study. It is seen that the peak at around $\omega / \omega_{M_{2}}=1.2-1.4$ is not shifted with changing boundary position, while the second peak is apparently boundary-dependent, because it is shifted from around a ratio of 3.1 to around 4.1 with the boundary moving up to the Channel head. This again indicates that the second peak should be the tidal response with the open boundary at the outer Channel. It is also worth noticing that the response amplitudes decrease with the boundary position moving from the ocean to the Channel head. The dominant resonant mode of the response $M_{2}$ in the Bristol Channel is hardly affected by the slight changing of boundary position.

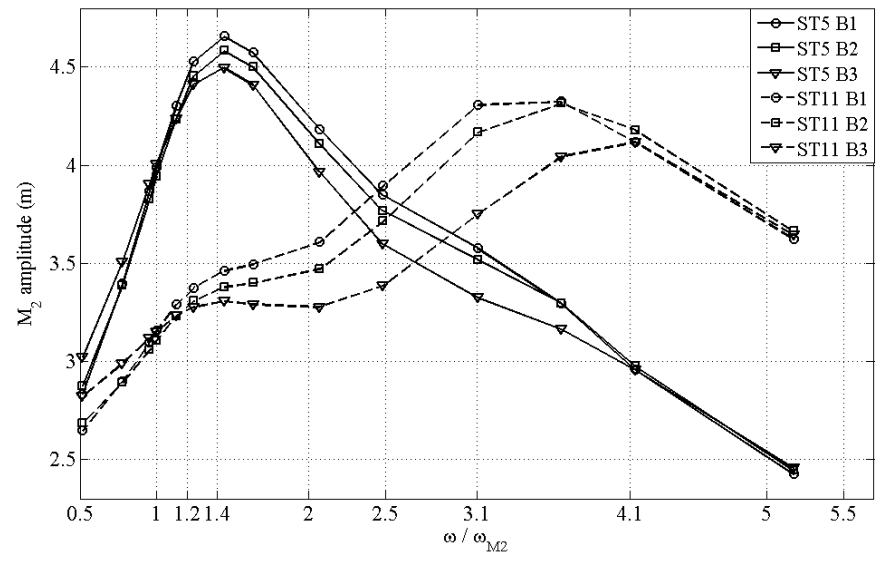

Fig. 6 Response curves of ST5 and STS11 with different boundary positions.

The Bristol Channel is a complex hydrodynamic system and sensitive to small changes. Factors such as bed friction can have influences on the resonant period. Fig. 7 shows that the amplitudes of $M_{2}$ response curves drop with increasing bed friction coefficient. However, we also find that the bed friction can affect the resonant period since a shift of the peak can be seen from a ratio of $\omega / \omega_{M_{2}}=1.3$ to 


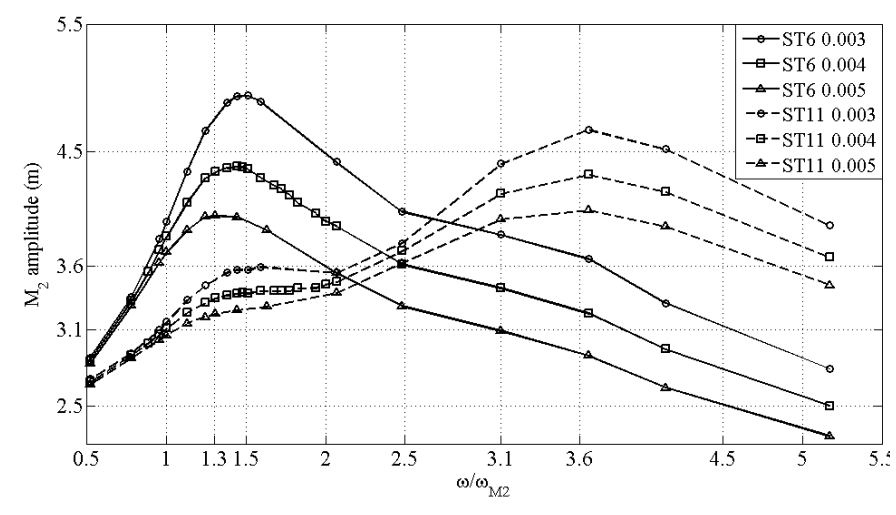

Fig. 7 Response curves of ST6 and ST11 with different bed frictions.

$\omega / \omega_{M_{2}}=1.5$. There is a great deal of interest in extracting energy from the Bristol Channel, and adding bottom friction would be a simplistic representation of additional dissipation in the model. This implies that the impact of resonances on the Channel should be taken into account by tidal energy development.

\section{Sensitivity Tests}

Tides in the Bristol Channel are very sensitive to changes in the physical system. The results of the sensitivity tests on water level, nodal factor and bed friction in both inner (ST5) and outer (ST11) parts of the Channel are shown in Fig. 8. The response tides are driven by tidal forcing of $M_{2}$ constituent.

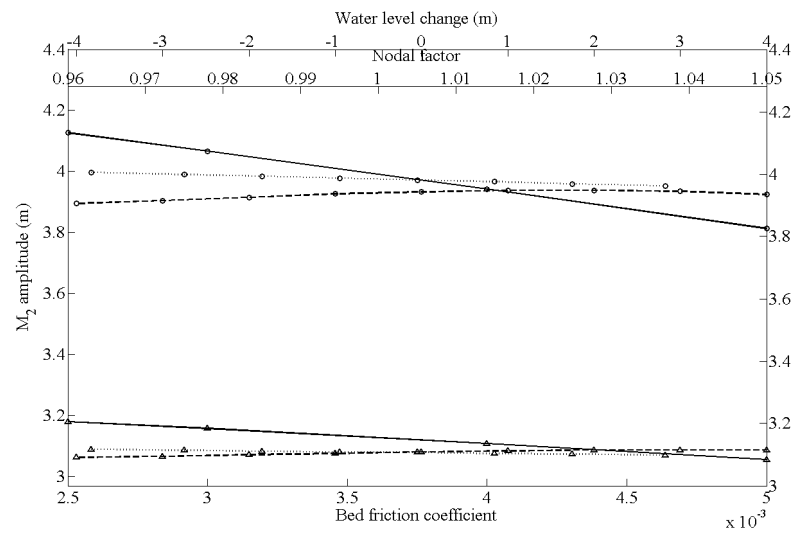

Fig. 8 Sensitivity test results on water level (dashed lines), nodal factor (dotted lines) and bed friction (solid lines) at ST5 (lines with circle markers) and ST11 (lines with triangle markers).

Sea level rise is the dominant influence on any far-field impacts and has influenced the tidal regimes in the past. Some modelling studies show even moderate sea level rise may have significant impact on the tides on the European shelf (Ward et al., 2012). In the present study, however, with water level varying from $4 \mathrm{~m}$ lower to $4 \mathrm{~m}$ higher than the real situation, the tidal heights do not present visible change in the Bristol Channel. The angle between the plane of the Moon's orbit around the earth and the plane through the equator of the Earth varies with a period of 18.6 years, and the nodal tidal cycle is usually represented as a linear modulating factor in the calculation of the tidal amplitudes (Adcock et al., 2014). Thus for the $M_{2}$ constituent:

$\eta_{M_{2}}=f_{M_{2}} \times a_{M_{2}} \cos \left(\omega_{M_{2}} t+\phi\right)$

where $\eta_{M_{2}}$ is the water level variation at the frequency of $M_{2}, f_{M_{2}}$ the nodal factor, $a_{M_{2}}$ the amplitude of the $M_{2}, \omega_{M_{2}}$ the frequency of the $M_{2}$ and $\phi$ its phase. $M_{2}$ was the only tidal constituent used in this model, therefore $f_{M_{2}}$ dominates the annual water level variation. Over a period of 9.3 years, the $M_{2}$ nodal factor changes from its minimum value 0.96 , to its maximum 1.04 ; however, during this time period the response of $M_{2}$ tidal heights almost remain unchanged. This suggests the response is essentially linear over the range of interest.

The bed friction is seen to be a dominant effect on the tidal response, since the $M_{2}$ amplitude at ST11 decreases by around $0.2 \mathrm{~m}$ with the quadratic friction coefficient increasing from 0.0025 to 0.005 . The bed friction has even greater influence on the shallower areas: at ST5 the amplitude change reaches more than $0.3 \mathrm{~m}$. In nature the forced resonant oscillations cannot grow indefinitely because the leakage of energy due to friction increases more rapidly than the amplitudes of the oscillations themselves. Tidal amplitude is strongly affected by frictional resistance especially in shallow channels. When friction is incorporated, the progressive waves are damped so that the elevation decreases with distance in the wave propagation direction, and the reflected waves may also travel along with lower amplitudes (Allen, 2009).

\section{Response to disturbances}

An alternative approach to investigating the resonant frequency is to examine the response to disturbances. In this case we apply a shear stress, which can be thought of as due to wind, and examine the subsequent oscillations. Simulations were run with winds from five different directions: South, Southwest, West, Northwest and North. In this section the modelling area (Fig.9) includes not only the Bristol Channel, but also the Celtic Sea, the Irish Sea and the English Channel, which is the same model used in Serhadlığlu's study (2014). Five locations in the upper Channel: Avonmouth, Hinkley Point, Newport, Ilfracombe and Mumbles were selected as the observation sites (Fig. 1). We simulate storms normally lasting 2 days (Day 7 to Day 9) during which the wind is $30 \mathrm{~ms}^{-1}$.

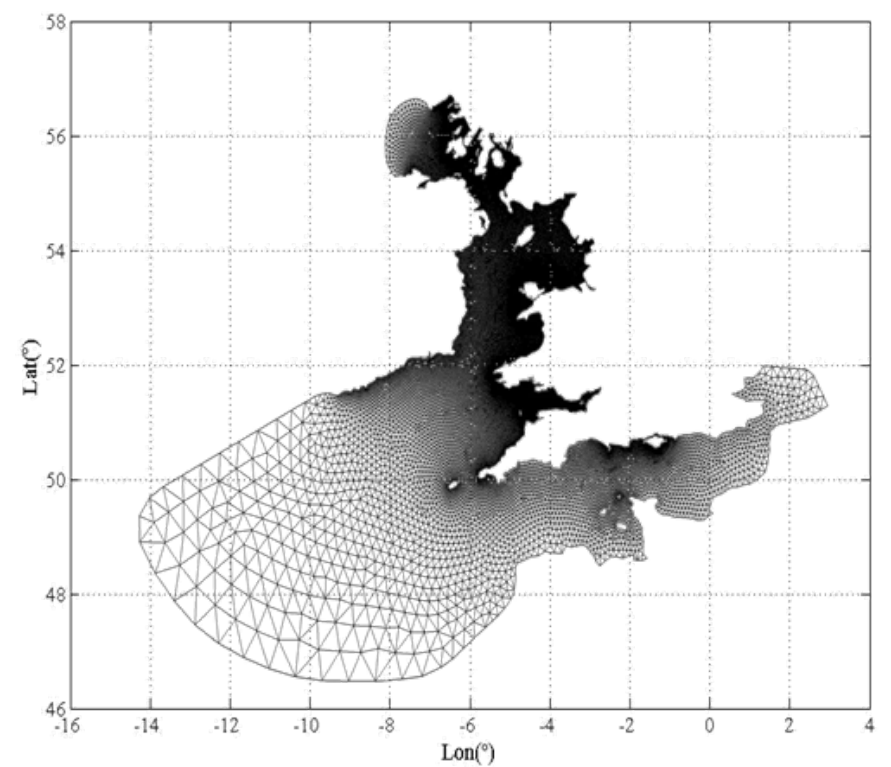

Fig. 9 Model mesh, including the Irish Sea, the Celtic Sea, the English Channel and the Bristol Channel.

On Day 9 the Southerly winds stops but it is seen in Fig. 10 that the surge overcompensates and becomes negative. From Day 10 the residuals display the development of oscillations with similar period and heights ranging from around $-0.2 \mathrm{~m}$ to $0.2 \mathrm{~m}$ in all the five sites. It takes around four days for the oscillations to settle. An explanation for the development of such oscillations would be a resonance phenomenon.

The Fast Fourier Transform (FFT) was used to analyse the frequencies present in the signal. Surge data from Day 11 to Day 14 (Fig. 10) was taken for FFT analysis. Fig. 11 shows the normalised magnitude spectrum by the amplitude response of the peak period over a period of surges that resulted from South-westerly winds 


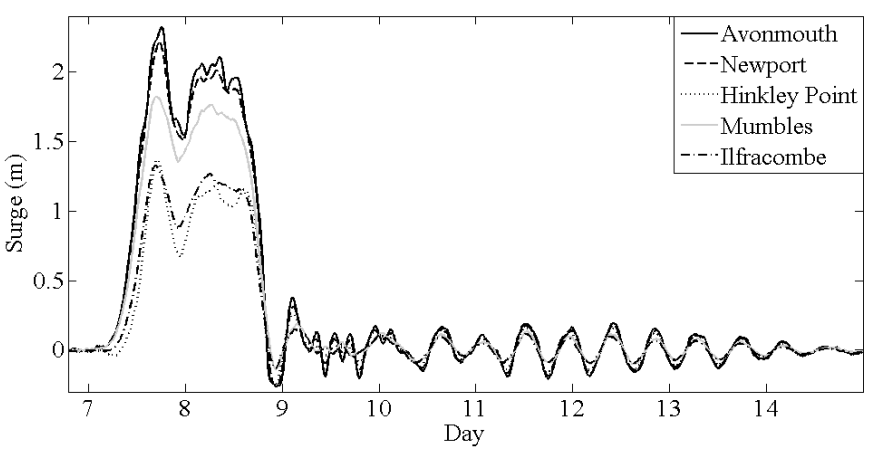

Fig. 10 Residuals calculated at 5 observation stations. Repetitive oscillations can be seen at all five stations after Southerly winds stop running.

in the Channel. A dominant peak can be seen which indicates the dominant oscillation period of around 10.3 hours. Similar results occurred when wind from different directions were used. This matches the resonance period of the Bristol Channel found in this study (8.87-10.35 hours). The resonant periods of 7.8 hours and 17 hours are also found but the cause is unclear. Webb (2013) investigated the resonances of the English Channel and Irish Sea by both running the model at angular velocities between 0 and 30 radians per day and running it with complex values of angular velocity. Both modelling results showed the key resonances have real angular velocity between 13 and 14 radians per day, which means the resonant period is between 10.8 and 11.6 hours. He also found the amplitude responses peaked between 20 and 30 radians per day, suggesting the resonant periods of 5 and 8 hours; however these modes have a more complicated structure and it was more difficult to relate the modes to specific physical features of the system. To conclude, the results in Fig. 11 indicate that the Bristol Channel is a coupled resonance system with a dominant resonant period of 10.3 hours. This is in close agreement with Webb's study and also Liang et al (2014) and Serhadlıoğlu (2014)'s, which suggested a coupled resonance system in the Bristol Channel.

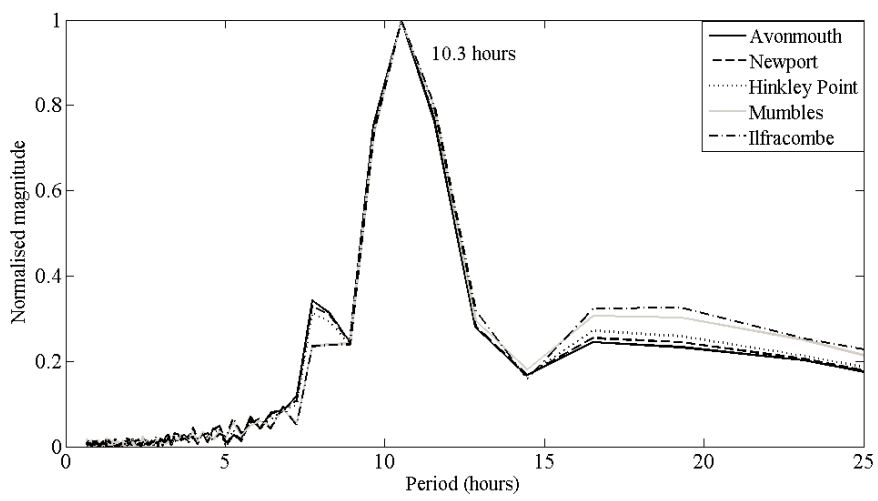

Fig. 11 Normalised magnitude spectrum over a period of surge with SouthWesterly winds imposed at five observation sites.

\section{CONCLUSIONS}

A two-dimensional shallow water model was used to study the tidal resonance in the Bristol Channel. The results from simulations with tide alone and wind alone show that the quarter-wavelength resonant period of the Bristol Channel has a coupled resonance system with dominant resonant period of 8.87-10.35 hours and 10.3 hours respectively. This is close to but shorter than the semi-diurnal tidal band, suggesting that the basin length of the Bristol Channel is shorter than the resonant quarter wavelength. Generally speaking, the main resonance of the Channel seems consistent with previous studies, and the second peak at about $\omega / \omega_{M_{2}}=3.1$ might be the resonant response of the outer Channel itself; the causes for the resonant periods of 7.8 hours and 17 hours found during wind disturbance simulations are unclear and future investigation is needed. The main resonance is slightly sensitive to increased bed friction which may have implications for tidal energy extraction. Neither the amplitude on the boundary nor the mean water level has a significant impact on the resonant response, suggesting that the nodal factor of the tide, or any possible sea-level rise, will not dramatically influence the tidal response in the Channel.

\section{ACKNOWLEDGEMENTS}

We are grateful to Dr. Sena Serhadlığlu who carried out a preliminary study of this topic in her DPhil project in the University of Oxford. She has also been a great support and help throughout the first year of this study.

\section{REFERENCES}

Adcock, TAA, Draper, S, Houlsby, GT, Borthwick, AGL, and Serhadlığlu, S (2014). "Tidal stream power in the Pentland Firth-long-term variability, multiple constituents and capacity factor,"Proceedings of the Institute of Mechanical Engineers, Part A, 228(8),854-861.

Adcock, TAA, Draper, S, and Nishino, T (2015). "Tidal power generation-a review of hydrodynamic modelling,"Proceedings of the Institution of Mechanical Engineers, Part A: Journal of Power and Energy, 0957650915570349.

Allen, PA (2009). Earth surface processes, JohnWiley \& Sons.

Baker, C (1991). “Tidal power, ”Energy Policy, 19(8), 792-797.

Bondi, H (1981). "Tidal Power from the Severn Estuary, vol. 2, ”Severn Barrage Committee Report to the Secretary of State for Energy

Falconer, R (1993). "An introduction to nearly horizontal flows,"Coastal, estuarial and harbour engineers reference book, 27-36.

Fong, S and Heaps, NS (1978). "Note on quarter-wave tidal resonance in the Bristol Channel".

Godin, G (1993). "On tidal resonance, "Continental Shelf Research, 13(1),89107.

Google Earth 7.1.7.2606 (2016). http://www.earth.google.com. 51 $03^{\prime} 02.37 ” N$, $3^{\circ} 50^{\prime} 40.98^{\prime} W$, Eye alt $199.53 \mathrm{~km}$. Landsat/Copernicus, viewed October 6 2016.

Hashemi, M, Abedini, M, Neill, S, and Malekzadeh, P (2008). "Tidal and surge modelling using differential quadrature: A case study in the Bristol Channel, "Coastal Engineering, 55(10),811-819.

Heath, R (1981). "Resonant period and Q of the Celtic Sea and Bristol Channel, "Estuarine, Coastal and Shelf Science, 12(3),291-301.

Kubatko, EJ, Westerink, JJ, and Dawson, C (2006). "hp discontinuous Galerkin methods for advection dominated problems in shallow water flow, "Computer Methods in Applied Mechanics and Engineering, 196(1),437-451.

Liang, D, Xia, J, Falconer, RA, and Zhang, J (2014). "Study on tidal resonance in Severn Estuary and Bristol Channel, "Coastal Engineering Journal, 56(01),1450002.

Marmer, HA (1922). "Tides in the Bay of Fundy, "Geographical Review, 12(2),195-205.

Pugh, D and Woodworth, P (2014). Sea-Level Science: Understanding Tides, Surges, Tsunamis and Mean Sea-Level Changes, Cambridge University Press.

Pugh, DT (1996). Tides, surges and mean sea-level (reprinted with corrections), John Wiley \& Sons Ltd.

Robinson, I (1980). "Tides in the Bristol Channel—an analytical wedge model with friction, "Geophysical Journal International, 62(1),77-95.

Serhadlığlu, S (2014). "Tidal stream resource assessment of the Anglesey Skerries and the Bristol Channel, "DPhil thesis, University of Oxford.

Serhadlığlu, S, Adcock, TAA, Houlsby, GT, Draper, S, and Borthwick, AGL (2013). "Tidal stream energy resource assessment of the Anglesey Skerries, "International Journal of Marine Energy, 3,e98-e111.

Ward, SL, Green, JM, and Pelling, HE (2012). "Tides, sea-level rise and tidal power extraction on the European shelf, "Ocean Dynamics, 62(8),1153-1167.

Webb, DJ (2013). "On the shelf resonances of the English Channel and Irish Sea, "Ocean Science, 9(4),731-744.

Willis, M, Masters, I, Thomas, S, Gallie, R, Loman, J, Cook, A, Ahmadian, R, Falconer, RA, Lin, B, Gao, G and Cross, M (2010). "Tidal turbine deployment in the Bristol Channel: a case study, "Proceedings of the Institution of Civil Engineers-Energy, 163(3),93-105.

Xia, J, Falconer, RA, Lin, B, and Tan, G (2012). "Estimation of annual energy output from a tidal barrage using two different methods, "Applied Energy, $93,327-336$ 